\title{
Allergy to titanium dental implants reality or a myth.
}

\section{Abstract}

Introduction: According to the phenomenon of osseointegration, titanium dental implants have been regarded as absolutely iocompatible and indifferent to the host despite the reports of hypersensitivity to titanium from others fields of medicine. For the las decade this problem has started to appear in the reports concerning allergy reactions to titanium dental implants as a background of complications. Material and Methods: A systematic review of English articles, which corresponded to inclusion criteria's, has been done. Access to the library resources of Goethe University in Frankfurt am Main, database of MEDLINE /PUBMED and also web page of MELISA FOUNDATION, were used. The search terms: implant, allergy, titanium, dental, implants, hypersensitivity, metal, reaction in various combinations and also with Boolean operators: AND, OR and NOT resulted in the highest score of 531 articles. Combination of key words: dental, titanium, implant, allergy, metal, reaction in database of PUBMED revealed 8 articles which became the basic for further searching's via bibliography lists. Results:531 articles were studied. The search resulted in a total of 36 studies. About local and neral symptoms associated with allergy to titanium dental implants reported 4 case reports and 2 clinical studies. Due to heavy allergic complication, one clinical study described allergic shock- glottis oedema after implant insertion. In one case report the patient ejected proposal of explantation of implants. The survival of titanium dental allergologically complicated implants ranged from 3 weeks up to 2 years ( 5 studies). Out of the allergological tests were conducted: Prick's test- 1 study, Patch tests 5 studies, LTT/MELISA - 3 studies. Histological evaluation of specimens was conducted in 2 studies. Two studies showed no allergic symptoms after insertion of titanium dental implants. One study proved/discovered probably mechanism of tolerance to titanium. Conclusion: Based on the collectec aterial it can be stated that a possibility of occurrence of allergy to titanium dental implants exists, especially in some specific for human body circumstances, such as $\mathrm{pH}$-value of surrounding fluids, close contact to dissimilar metals, wear and fatigue of material. Stil inadequacy of patch tests for detection of allergy to titanium dental implants exists. It seems, that MELISA test is the best solution in searching's titanium allergy and this method should be performed as a first in suspicious cases. It also seems that the new look at eriimplantitis and revision of knowledge in that matter is a must. The perimplantitis=allergy (of IV type due to classification of Gell and Coombs). Probably exists the cure for chronic inflammatory diseases-titanium in the form of dust (for example, implantation of rutiles of fanium grade I into the BALT system should protect against attacks of the asthma- due to Interleukin-10 overproduction).

\begin{tabular}{|l|l|}
\hline $\begin{array}{l}\text { Elements of the } \\
\text { Grade I Jitanium }\end{array}$ & \% by weight \\
\hline Titanium (Ti) & 99,6 \\
\hline Iron (Fe) & 0,20 \\
\hline Oxygen (O) & 0,40 \\
\hline Nitrogen (N) & 0,03 \\
\hline Carbon (c) & 0,08 \\
\hline Hydrogen (H) & 0,015 \\
\hline Residual ions & Max 0,30 \\
\hline
\end{tabular}

Chart 1. Chemical composition of the grade titanium. ASTM-F67-standard specyfication

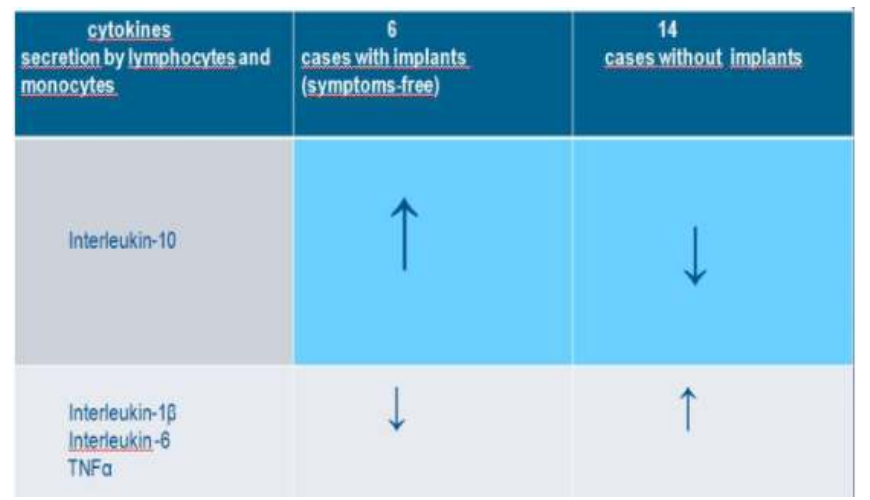

Chart 2. Cytokines production during LTT tests with titanium particles based onThomas et al.

\section{Background and Aim}

According to the phenomenon of osseointegration, titanium dental implants have been regarded as absolutely biocompatible and indifferent to the host despite the reports of hypersensitivity to titanium from others fields of medicine. For the last decade this problem has started to appear in the reports concerning allergy reactions to titanium dental implants as a background of the complications.

\section{Results}

Due to including criteria 531 articles were studied. The search resulted in a total of 36 studies. About local (facial eczema, mucositis, rush, swelling, hyperaemia of close soft tissues, pain and unexplained implants exfoliation) and general (muscle, joint and nerve pain, chronic fatigue syndrome, neurological problems) symptoms associated with allergy to titanium dental implants reported 4 case reports and 2 clinical studies. Due to heavy allergic complication, one clinical study described allergic shock- glottis oedema after implant insertion. In one case report the patient rejected proposal of explantation of implants. Survival of titanium dental allergologically complicated implants ranged from 3 weeks up to 2 years ( 5 studies). Out of the allergological tests were conducted: Prick's test- 1 study, Patch tests 5 studies, LTT/MELISA - 3 studies. Histological evaluation of specimens was conducted in 2 studies. Two studies showed no allergic symptoms after insertion of titanium dental implants. One study proved/discovered probably mechanism of tolerance to titanium.

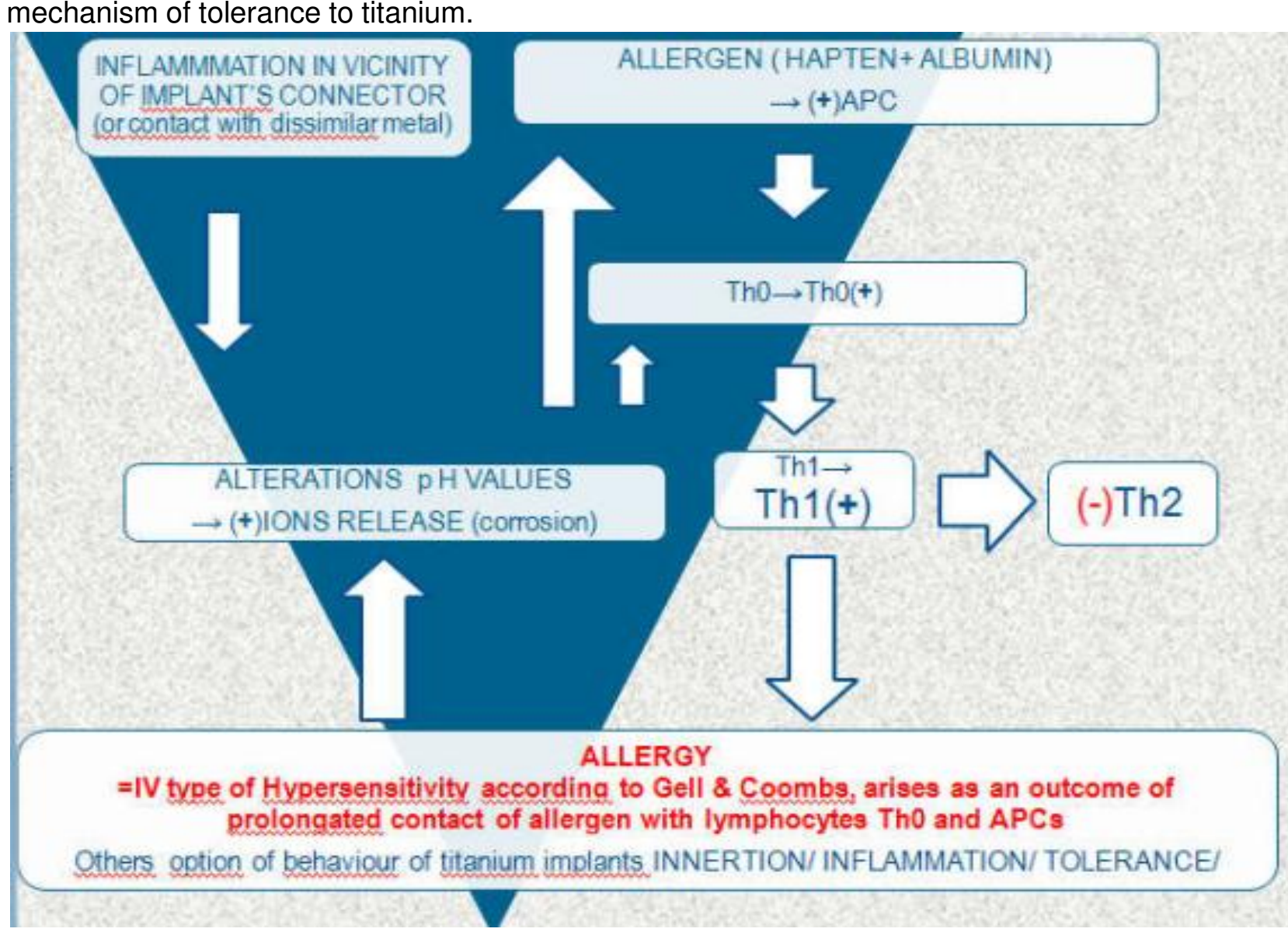

Diagram 1. The vicious circle of reactions in the vicinity of the titanium dental implant. Periimplantitis= DTH-a proposition of the authors.

\section{Conclusion}

Based on the collected material it can be stated that a possibility of occurrence of allergy to titanium dental implants exists, especially in some specific for human body circumstances, such as $\mathrm{pH}$-value of surrounding fluids, close contact to dissimilar metals, wear and fatigue of material. Still inadequacy of patch tests for detection of allergy to titanium dental implants exists. It seems, that MELISA test is the best solution in searching's titanium allergy and this method should be performed as a first in suspicious cases It also seems that the new look at periimplantitis and revision of knowledge in that matter is a must. The periimplantitis=allergy (of IV type due to classification of Gell and Coombs).

CLINICAL IMPLICATION: In our opinion exists the cure for chronic inflammatory diseases-titanium in the form of dust (for example, implantation of rutiles of titanium grade I into the BALT system should protect against attacks of the asthma- due to Interleukin-10 overproduction).

A systematic review of English articles, which corresponded to inclusion criteria's, has been done. Access to the library resources of Goethe University in Frankfurt am Main, database of MEDLINE /PUBMED and also web page of MELISA FOUNDATION, were used. The search terms: implant, allergy, titanium, dental, implants, hypersensitivity, metal, reaction in various combinations and also with Boolean operators: AND, OR and NOT resulted in the highest score of 531 articles. Combination of key words: dental, titanium, implant, allergy, metal, reaction in database of PUBMED revealed 8 articles which became the basic for further searching's via bibliography lists.
1.Du Preez, L A; Butow, K. W.; Swart, T J P (2007): Implant failure due to titanium hypersensitivity/allergy?--Report of a case. W: SADJ 62 (1), s.22, 2.-Egusa, Hiroshi; Ko, Nagakazu; Shimazu, Tsunetoshi; Yatani, Hirofumi (2008): Suspected association of an allergic reaction with titanium denta implants: a clinical report. w: J Prosthet Dent 100 (5), s. 344-347.
int 3.Flatebø, Rigmor S.; Johannessen, Anne C.; Grønningsaeter, Arne G.; Bøe, Olav E.; Gjerdet, Nils R.; Grung, Bjarte; Leknes, Knut N. (2006): Hos response to titanium dental implant placement evaluated in a human oral model. W: Journal of periodontology 77 (7), s. 1201-1210.
$4 . \mathrm{Lim}$. Hyun-Pil; Lee, Kwang-Min; Koh, Young-lli Park, Sang-Won (2012): Allergic contact stomatitis caused by a titanium nitride-coated implan 4.Lim, Hyun-Pil; Lee, Kwang-Min; Koh, Young-ll; Park, Sang-Won 5.Muller, Kurt; Valentine-Thon, Elizabeth (2006): Hypersensitivity to titanium: clinical and s. 31-35
6.Pigatto, Paolo D.; Berti, Emilio; Spadari, Francesco; Bombeccari, Gian Paolo; Guzzi, Gianpaolo (2011): Photoletter to the editor: Exfoliative 7. Sicililia, Alberto; Cuesta, Susana; Coma Gerardo; Arregui, Ignacio: Guisasola Cristina; Ruiz. Eduardo: Maestro, Antonio (2008): Titanium allergy 7. Sicilia, Alberto; Cuesta, Susana; Coma, Gerardo; Arregui, Inacio; Guisasola, Cristina; Ruiz, Eduardo; Maestro, Ant
in dental implant patients: a clinical study on 1500 consecutive patients. w: Clin Oral Implants Res 19 (8), s. 823-835. 8.Thomas, Peter; Iglhaut, Gerhard; Wollenberg, Andreas; Cadosch, Dieter; Summer, Burkhard (2013): Allergy or tolerance: reduced inflammatory cytokine response and concomitant L-10 production of lymphocytes and monocytes in symptom-free titanium dental implant patients. w: BioMed
research international $2013, \mathrm{~s} .539834$. 